\title{
Effects of a reminder to initiate oral anticoagulation in patients with atrial fibrillation/atrial flutter discharged from the emergency department: REMINDER study
}

\author{
Saman Rezazadeh*; Derek S. Chew*; Robert J.H. Miller*; Sheila Klassen*; Payam Pournazari ${ }^{\dagger}$; \\ Graham Bennett*; Eddy Lang ${ }^{\ddagger}$; F. Russell Quinn*
}

\begin{abstract}
CLINICIAN'S CAPSULE
What is known about the topic?

Oral anticoagulation (OAC) reduces stroke risk in patients with atrial fibrillation or flutter; however, initiation rates in patients discharged from the ED are low.

What did this study ask?

Can a simple quality improvement intervention increase the initiation of appropriate OAC in the ED?

What did this study find?

The rate of OAC initiation was increased by $8.5 \%$.

Why does this study matter to clinicians?

This simple intervention is transferrable and therefore can improve patient care.
\end{abstract}

\section{ABSTRACT}

Objective: Oral anticoagulation (OAC) reduces stroke risk in patients with atrial fibrillation (AF) or atrial flutter (AFL). However, OAC initiation rates in patients discharged directly from the emergency department (ED) are low. We aimed to address this care gap by implementing a quality improvement intervention.

Methods: The study was performed in four Canadian urban EDs between 2015 and 2016. Patients were included if they had an electrocardiogram (ECG) documenting AF/AFL in the ED, were directly discharged from the ED, and were alive after 90 days. Baseline rates of OAC initiation were determined prior to the intervention. Between June and December 2016, we implemented our intervention in two EDs (ED-intervention), with the remaining sites acting as controls (ED-control). The intervention included a reminder statement prompting OAC initiation according to guideline recommendations, manually added to ECGs with a preliminary interpretation of $A F / A F L$, along with a decision-support algorithm that included a referral sheet. The primary outcome was the rate of OAC initiation within 90 days of the ED visit.
Results: Prior to the intervention, 37.2\% OAC-naïve patients with ECG-documented AF/AFL were initiated on OAC. Following implementation of the intervention, the rate of OAC initiation increased from $38.6 \%$ to $47.5 \%$ (absolute increase of $8.5 \% ; 95 \% \mathrm{Cl}, 0.3 \%$ to $16.7 \%, p=0.04)$ among the EDintervention sites, whereas the rate remained unchanged in ED-control sites (35.3\% to $35.9 \%, p=0.9$ ).

Conclusions: Implementation of a quality improvement intervention consisting of a reminder and decision-support tool increased initiation of OAC in high-risk patients. This support package can be readily implemented in other jurisdictions to improve OAC rates for AF/AFL.

\section{RÉSUMÉ}

Contexte: L'anticoagulation par voie orale $(A O)$ diminue le risque d'accident vasculaire cérébral chez les patients atteints de fibrillation auriculaire (FA) ou de flutter auriculaire (FIA). Toutefois, le taux de formation initiale à l'AO parmi les patients qui obtiennent leur congé directement du service des urgences (SU) est bas. Aussi l'étude visait-elle à combler cette lacune en matière de soins par la mise en œuvre d'une intervention d'amélioration de la qualité.

Méthode: L'étude a été menée dans quatre SU situés en milieu urbain, au Canada, entre 2015 et 2016. Les patients étaient retenus si la présence de FA ou de FIA avait été confirmée à l'électrocardiogramme (ECG) au SU, s'ils avaient obtenu leur congé directement du SU et s'ils étaient encore vivants au bout de 90 jours. Le taux de formation initiale à I'AO a été établi au départ avant l'intervention; celle-ci a ensuite été appliquée entre juin et décembre 2016 dans deux SU (SU expérimentaux), tandis que les deux autres ont servi de points de comparaison (SU témoins). L'intervention consistait en un rappel, écrit à la main sur les ECG qui faisaient état au premier abord de FA ou de FIA, de la formation initiale à I'AO suivant les recommandations formulées dans des lignes directrices et en un algorithme d'aide à la décision qui comprenait un formulaire de consultation. Le principal critère d'évaluation était le taux de

From the *Libin Cardiovascular Institute of Alberta, Department of Cardiac Sciences, University of Calgary, Calgary, AB; $†$ Departments of ${ }^{\dagger}$ Medicine; and $\neq$ Emergency Medicine, University of Calgary, Calgary, AB.

Correspondence to: Dr. F. Russell Quinn, GAC82 HRIC, 3280 Hospital Drive NW, Calgary, AB T2N 4Z6; Email: frquinn@ucalgary.ca 
formation initiale à I'AO dans les 90 jours suivant la consultation au SU.

Résultats: Avant l'intervention, le taux de formation initiale à l'AO chez les patients atteints de FA ou de FIA avérés à I'ECG et jamais soumis auparavant à ce type de traitement était de $37,2 \%$. Après la mise en œuvre de l'intervention, le taux de formation initiale à I'AO est passé de 38,6\% à 47,5\% (augmentation absolue : 8,5\%; IC à $95 \%: 0,3-16,7 \% ; p=0,04)$ dans les SU expérimentaux, tandis qu'il est resté stable dans les SU témoins $(35,3 \%-35,9 \% ; p=0,9)$.
Conclusion: La mise en œuvre de l'intervention d'amélioration de la qualité, consistant en un rappel et en un outil d'aide à la décision, a permis d'accroître le taux de formation initiale à I'AO chez les patients à risque élevé. Ce type de mesure est facilement applicable dans d'autres services ou établissements afin d'améliorer le taux de formation initiale à I'AO dans les cas de FA ou de FIA.

Keywords: Atrial fibrillation, stroke, anticoagulation, emergency department
Rates of oral anticoagulation (OAC) initiation in patients with atrial fibrillation (AF) or atrial flutter (AFL) directly discharged from the emergency department (ED) are low. We implemented a quality improvement intervention consisting of a reminder statement prompting OAC initiation, manually added to electrocardiograms with a preliminary AF/AFL interpretation. There was an $8.5 \%$ absolute increase in the rate of appropriate OAC initiation. This support package is transferrable and can be readily implemented in other EDs to improve OAC rates for AF/AFL.

\section{INTRODUCTION}

Atrial fibrillation (AF) and atrial flutter (AFL) are independent risk factors for stroke and systemic embolism, increasing risk by fivefold in all age groups. ${ }^{1}$ The percentage of strokes attributable to AF/AFL increases from $1.5 \%$ at 50 to 59 years of age to more than $20 \%$ in patients ages 80 to 89 years. ${ }^{2}$ Furthermore, strokes attributed to AF/AFL are associated with a higher recurrence rate, disability, and mortality. ${ }^{3}$ Multiple studies have demonstrated the benefit of oral anticoagulation (OAC) for stroke prevention in $\mathrm{AF} /$ AFL patients. ${ }^{4-7}$ The current Canadian Cardiovascular Society (CCS) guidelines endorse use of the "CHADS65" risk scoring system, with OAC being recommended for all patients ages $\geq 65$ years or having one or more risk factors (congestive heart failure, hypertension, diabetes, or stroke/transient ischemic attack/systemic embolism). ${ }^{2}$

AF/AFL are the most common arrhythmias presenting to the emergency department (ED). ${ }^{8-10}$ Many patients are discharged directly from the ED, placing ED physicians in a unique position to initiate guidelinedirected OAC therapy for these patients. In fact, ED initiation of OAC is associated with improved longterm adherence. ${ }^{11}$ Despite this, the rate of appropriate initiation of OAC in patients discharged from EDs remains consistently low, as shown by a multicentre prospective study conducted in 124 Spanish EDs and a retrospective assessment of two EDs in Vancouver, where only $45 \%$ and $47 \%$ of patients, respectively, were initiated on OAC. ${ }^{12,13}$ In a recent study conducted in three EDs in Winnipeg, the rate of newly filled OAC prescriptions for appropriate anticoagulation of actionable $\mathrm{AF}$ was $32 \%$ at a 90 -day, post-ED visit. ${ }^{14}$ Suboptimal rates of initiating appropriate OAC therapy represent a missed opportunity in the ED; however, there are few studies exploring the efficacy and safety of interventions aimed to increase the appropriate use of OAC therapy for AF/AFL detected in the ED.

We investigated the impact of an OAC reminder, coupled with a simple decision-making support package, on the rate of initiating appropriate OAC therapy in patients with AF/AFL discharged from the ED.

\section{METHODS}

\section{Study setting and study population}

The study was performed in the four adult EDs in Calgary, Alberta, which serve a population of approximately 1.2 million people. All of these EDs are part of teaching hospitals with access to consulting specialists, including internists and cardiologists. Between January 1, 2015, and December 31, 2016, all patients with a 12lead electrocardiogram (ECG) documenting AF/AFL performed in the ED were identified using the MUSE database (GE Healthcare, Wauwatosa, WI). Patient comorbidities (including congestive heart failure, hypertension, diabetes, ischemic, or hemorrhagic stroke) were determined through linkage with the Calgary Health Region discharge abstract database, as previously described. ${ }^{15}$ Additionally, patients' electronic medical records were reviewed manually to confirm the 
accuracy of extracted data and to determine the status of hospital admission or direct discharge from the ED. Patients with valvular AF/AFL, defined as the presence of rheumatic mitral stenosis, prosthetic heart valve, or mitral valve repair, ${ }^{16,17}$ were excluded from the analysis. Patients with non-valvular AF/AFL were considered eligible for anticoagulation with a CHADS65 score of $\geq 1$, consistent with current CCS AF/AFL guidelines. ${ }^{17}$ The primary study cohort consisted of patients who were discharged directly from the ED with ECGdocumented AF/AFL, not previously prescribed OAC therapy, despite eligibility or not previously known to have AF/AFL.

\section{Study design}

The reminder study had a prospective design, using an observational cohort to obtain baseline data, and an interventional cohort to test the effects of a quality improvement intervention. During the pre-intervention observational phase (January 1 to December 31, 2015), we determined existing rates of OAC use prior to ED presentation and within 90 days of discharge. The intervention was implemented in two of the EDs (EDintervention), with each serving an average annual patient volume of 82,000 and 79,000 on May 1, 2016, with a planned 1-month run-in phase and prospective data collection starting on June 1. To account for possible temporal changes in OAC prescription rates, data were also collected from the remaining two EDs, where no intervention was performed (ED-control), each serving an approximate annual patient volume of 78,000 and 65,000. The ED pairings were chosen based on usual staff work patterns to minimize the chance of individual ED physicians working at both ED-intervention and ED-control sites. This study was approved by the Conjoint Health Research Ethics Board of the University of Calgary and conducted in accordance with the Declaration of Helsinki. Individual patient consent was waived due to the nature of the study design.

\section{Intervention}

Any 12 lead-ECG with a preliminary, machine-generated, interpretation of AF/AFL had a sticker manually applied, stating: "If physician-confirmed AF, consider initiation of oral anticoagulation as indicated based on CCS 2014 guidelines" (see Supplemental Figure 1). Additionally, a one-page AF/AFL decision-support package containing the CCS algorithm for deciding on antithrombotic therapy in non-valvular AF/AFL, and risk factors for bleeding, was attached to the ED chart (see Supplemental Figure 1). Additionally, the package contained a simplified referral form to two previously established outpatient cardiology clinics with a focus on management of patients with AF/AFL to facilitate outpatient consultation (see Supplemental Figure 2). Other than directly attaching the referral forms to the appropriate ED charts, the process of outpatient referral was not altered. To validate the preliminary ECG machine rhythm interpretation, 200 ECGs were randomly selected and reviewed by a cardiac electrophysiologist F. Russell Quinn [FRQ].

\section{Primary outcome}

The primary outcome was the rate of pharmacy-filled OAC prescriptions among patients with AF/AFL and CHADS65 score of $\geq 1$ within 90 days of the index ED visit. The rate of filled OAC prescriptions (i.e., warfarin, rivaroxaban, dabigatran, or apixaban) was determined through linkage to the provincial Pharmacy Information Network, which prospectively collects dispensed medication information from more than $95 \%$ of all pharmacies in the province of Alberta. Pre-existing OAC therapy was defined as a filled OAC prescription within the 180 days preceding ED presentation. We also examined prescription rates of OACs in low-risk patients (i.e., CHADS65 score of zero) to assess for a possible change in OAC prescription rates as a result of the intervention. Specifically, we wanted to assess whether rates of inappropriate anticoagulation in low-risk patients increased inadvertently as a product of the intervention.

\section{Statistical analysis}

Continuous variables are presented as a median and standard deviation. Categorical data are expressed as absolute numbers and percentages. Analysis of variance (parametric) and the Kruskal-Wallis test (non-parametric) were used to compare continuous variables, whereas the Pearson $\chi 2$ test was used to compare categorical variables. We compared differences in our primary outcome, OAC initiation within 90 days, prior to and after implementation of our intervention. Analyses were pre-specified and performed in the cohort of patients surviving beyond 90 days of an ED encounter. Factors associated with a prescription of guideline- 
appropriate $\mathrm{OAC}$ in AF/AFL patients discharged from the ED were assessed using bivariate and multivariable logistic regression analysis from which odds ratios and 95\% confidence intervals (CI) were obtained.

Based on previous studies with an expected baseline OAC prescription rate of $47 \%,{ }^{13}$ and the intervention population representing 0.36 of the total population (7 months intervention v. 12 months pre-intervention), a sample size of 892 patients (571 pre-intervention, 321 post-intervention) would have a power of $80 \%$ to detect a $10 \%$ absolute increase in appropriate OAC rates, with an alpha level of 0.05 . We anticipated that enrolment would be completed by December 31, 2016. However, upon stopping the study, it became apparent that more patients were admitted or were already on OAC than we expected during the intervention phase. Analyses were completed with those enrolled during the planned study period. All analyses were performed using Stata 15.1 (Stata Corp., College Station, Texas). All statistical tests were two-sided, with $p$ values $<0.05$ considered significant.

\section{RESULTS}

\section{Baseline rates of anticoagulation amongst patients with AF/AFL discharged from the ED}

During the observational phase (January 1 to December 31, 2015), there were 4,948 patients with documented $\mathrm{AF} / \mathrm{AFL}$ during an ED visit across the four sites; 2,130 (43.0\%) patients were discharged directly from the ED. Of the patients discharged from the ED, 713 (33.5\%) patients were previously not on OAC and had a CHADS65 score of $\geq 1$. Within 90 days of discharge from the ED, only $265(37.2 \%)$ patients were initiated on OAC therapy. In a random sample of 200 ECGs with an initial computer interpretation of AF/AFL, the rhythm interpretation was correct in 199 (99.5\%) when reviewed by a cardiac electrophysiologist (FRQ).

\section{Effect of intervention on rates of a new OAC prescription within 90 days of ED discharge}

Table 1 summarizes the characteristics of subjects before and after the intervention in the ED-control and ED-intervention sites. No significant differences were present in any of the baseline characteristics. Following implementation of the intervention, the rate of appropriate initiation of OAC increased from $38.7 \%$ to

\begin{tabular}{|c|c|c|c|}
\hline & $\begin{array}{l}\text { Pre-intervention } \\
\quad n=414\end{array}$ & $\begin{array}{l}\text { Post-intervention } \\
\qquad n=212\end{array}$ & $\begin{array}{c}p \\
\text { value }\end{array}$ \\
\hline Age $\pm S D$, years & $74.7 \pm 12.4$ & $73.4 \pm 13.2$ & 0.4 \\
\hline Female - No. (\%) & $173(41.8)$ & $104(49.1)$ & 0.08 \\
\hline Heart failure - No. $(\%)$ & $83(20.1)$ & 40 (18.9) & 0.7 \\
\hline Hypertension - No. (\%) & $231(55.8)$ & $122(57.6)$ & 0.7 \\
\hline Diabetes - No. (\%) & 81 (19.6) & $49(23.1)$ & 0.3 \\
\hline Ischemic stroke - No. (\%) & $60(14.5)$ & $23(10.9)$ & 0.2 \\
\hline CHADS65 $($ mean \pm SD) & $2.05 \pm 1.13$ & $1.94 \pm 1.06$ & 0.3 \\
\hline $0-$ No. $(\%)$ & - & - & 0.8 \\
\hline 1 - No. (\%) & $161(38.9)$ & $92(43.4)$ & \\
\hline 2 - No. $(\%)$ & $141(34.1)$ & 67 (31.6) & \\
\hline 3 - No. (\%) & $63(15.2)$ & $30(14.1)$ & \\
\hline$\geq 4-$ No. $(\%)$ & 49 (11.8) & $23(10.9)$ & \\
\hline $\begin{array}{l}\text { AF as primary diagnosis - } \\
\text { No. }(\%)\end{array}$ & $183(44.2)$ & $88(41.5)$ & 0.6 \\
\hline $\begin{array}{l}\text { Hemorrhagic stroke - No. } \\
(\%)\end{array}$ & $9(2.2)$ & $3(1.4)$ & 0.5 \\
\hline
\end{tabular}

$47.2 \%$, an absolute increase of $8.5 \%$ (95\% CI, $0.3 \%$ to $16.7 \%, p=0.041$; Table 2, Figure 1). In the ED-control sites, over the same study period, there was no change in the rates of OAC prescription (see Table 2, Figure 1). During the intervention period, the rate of appropriate initiation of $\mathrm{OAC}$ in the ED-intervention sites was significantly higher than at the ED-control sites $(p=0.020)$. Rates of OAC initiation in patients with a CHADS65 score of 0 did not change in any site during the intervention period (see Table 2). Among patients initiated on OAC therapy, direct OACs constituted $60 \%$ of prescriptions filled (i.e., rivaroxaban $27 \%$, apixaban $25 \%$ and dabigatran $8 \%$ ).

To evaluate the impact of mortality on the results, a secondary analysis was performed that included patient deaths within 90 days (i.e., deaths prior to assessment of the primary outcome at 3 months). The mortality at 3 months in the ED-intervention group was similar at pre- and post-implementation of the reminder intervention $(6.8 \%$ v. $8.2 \%, p=n s)$. Similarly, the 3 -month mortality in the ED-control group were also comparable pre- and post-implementation $(8.8 \%$ v. $13.8 \%$, $p=\mathrm{ns})$. The magnitude of effect post-implementation intervention was similar to the primary analysis; the rate of appropriate initiation of OAC increased from $36.8 \%$ to $45.9 \%, p=0.02$. Further, in our secondary analysis, there was no change in the rates of OAC in the ED- 


\begin{tabular}{|c|c|c|c|c|}
\hline \multirow[b]{2}{*}{ ED site } & \multirow[b]{2}{*}{ Patient group } & \multicolumn{2}{|c|}{ Rate of new OAC initiation } & \multirow[b]{2}{*}{$p$ value } \\
\hline & & Observation phase & Intervention phase & \\
\hline \multirow[t]{2}{*}{ ED-intervention } & CHADS65 $\geq 1$ & $38.7 \%(160 / 414)$ & $47.2 \%(100 / 212)$ & 0.04 \\
\hline & CHADS65 $=0$ & $9.8 \%(16 / 164)$ & $12.2 \%(10 / 82)$ & 0.6 \\
\hline \multirow[t]{2}{*}{ ED-control } & CHADS65 $\geq 1$ & $35.1 \%(105 / 299)$ & $35.8 \%(69 / 193)$ & 0.9 \\
\hline & CHADS65 $=0$ & $10.2 \%(12 / 118)$ & $17.0 \%(9 / 53)$ & 0.2 \\
\hline
\end{tabular}

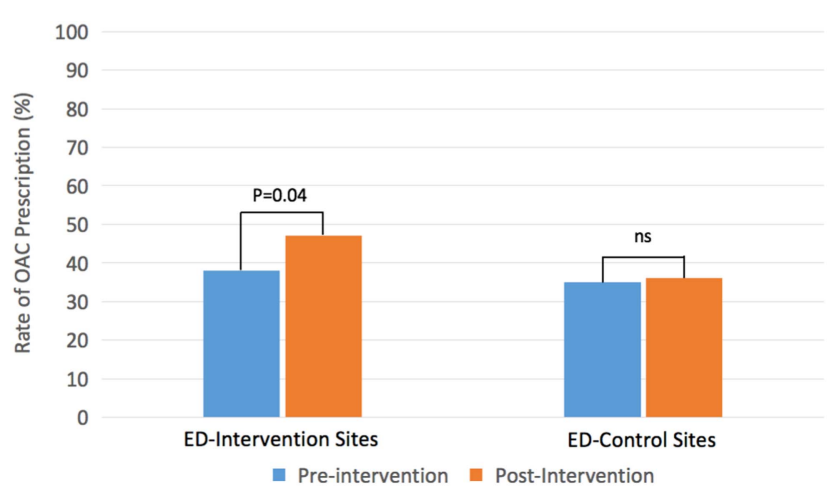

Figure 1. Rates of new $O A C$ prescription in patients with non-valvular $A F / A F L$, discharged from the ED, with a CHADS65 score of $\geq 1$ and alive at 90 days.

Legend: ED-Intervention - emergency departments where the intervention was implemented. ED-Control - emergency departments that did not undergo implementation of the intervention. Abbreviations: $A F / A F L=$ atrial fibrillation/atrial flutter; $E D=$ emergency department; $\mathrm{OAC}=$ oral anticoagulation.

control site. In summation, the inclusion or exclusion of patient deaths prior to outcome assessment at 3 months did not affect the magnitude of benefit that the reminder intervention conferred.

An exploratory analysis was conducted to assess whether the CHADS65 score had an impact on the rates of OAC initiation. Among OAC-naïve patients with lower CHADS65 scores of 1 or 2 in the EDintervention sites, there was a significant increase in the rate of OAC initiation $(37.4 \%$ to $50.3 \%, p=0.008$ ). However, there was no significant change in anticoagulation rates among patients with CHADS65 scores greater than $2(42.0 \%$ to $37.7 \%, p=0.6)$.

\section{Predictors of OAC initiation in eligible patients discharged from the ED}

Table 3 compares characteristics of those eligible patients who were or were not started on OAC within 90 days of

\begin{tabular}{|c|c|c|c|}
\hline & $\begin{array}{r}\text { OAC pr } \\
\text { dispensed } v\end{array}$ & $\begin{array}{l}\text { scription } \\
\text { ithin } 90 \text { days }\end{array}$ & \\
\hline & $\begin{array}{c}\text { Yes } \\
n=434\end{array}$ & $\begin{array}{c}\text { No } \\
n=684\end{array}$ & $p$ value \\
\hline $\mathrm{Age} \pm \mathrm{SD}$ & $74.4 \pm 10.6$ & $76.4 \pm 13.9$ & 0.002 \\
\hline Female - No. (\%) & $201(46.3)$ & $293(42.8)$ & 0.3 \\
\hline Heart failure - No. (\%) & $66(15.2)$ & $174(25.4)$ & $<0.001$ \\
\hline Hypertension - No. (\%) & $246(56.7)$ & $394(57.6)$ & 0.8 \\
\hline Diabetes - No. (\%) & $80(18.4)$ & $142(20.8)$ & 0.3 \\
\hline Ischemic stroke - No. (\%) & 56 (12.9) & 88 (12.9) & 0.9 \\
\hline CHADS65 (mean \pm SD) & $1.99 \pm 1.04$ & $2.10 \pm 1.16$ & 0.3 \\
\hline $0-$ No. $(\%)$ & - & - & 0.2 \\
\hline 1 - No. (\%) & $165(38.0)$ & 257 (37.6) & \\
\hline 2 - No. (\%) & $163(37.6)$ & $223(32.6)$ & \\
\hline 3 - No. $(\%)$ & $62(14.3)$ & $123(18.0)$ & \\
\hline$\geq 4-$ No. (\%) & $44(10.1)$ & 81 (11.8) & \\
\hline $\begin{array}{l}\text { AF as primary diagnosis - } \\
\text { No. }(\%)\end{array}$ & $253(58.3)$ & $206(30.1)$ & $<0.001$ \\
\hline $\begin{array}{l}\text { Hemorrhagic stroke - No. } \\
(\%)\end{array}$ & $4(0.92)$ & $18(2.63)$ & 0.05 \\
\hline $\begin{array}{l}\text { Reminder intervention - No. } \\
(\%)\end{array}$ & $100(23.0)$ & $112(16.4)$ & 0.006 \\
\hline
\end{tabular}

ED discharge during the entire study period. Patients who were initiated on OAC therapy were younger, more likely to have $\mathrm{AF} / \mathrm{AFL}$ as their primary diagnosis, and less likely to have a history of heart failure or hemorrhagic stroke. We performed a multivariate analysis to determine the independent predictors of OAC initiation (Table 4). Patients presenting with a primary diagnosis of $\mathrm{AF} / \mathrm{AFL}$ were three times more likely to be initiated on OAC compared to those where it was a secondary diagnosis. The reminder intervention was independently associated with a 1.5 -fold increase in appropriate OAC therapy 


\begin{tabular}{|c|c|c|c|c|}
\hline & $\begin{array}{c}\text { Bivariate } \\
\text { HR }(95 \% \text { Cl) }\end{array}$ & $p$ value & $\begin{array}{l}\text { Multivariable }^{*} \\
\text { HR }(95 \% \mathrm{Cl})\end{array}$ & $p$ value \\
\hline Age (per 10 years) & $0.88(0.80,0.97)$ & 0.01 & $0.99(0.89,1.10)$ & NS \\
\hline Female & $1.15(0.90,1.47)$ & NS & $1.03(0.79,1.34)$ & NS \\
\hline CHADS65 score (per point) & $0.92(0.82,1.0)$ & NS & - & - \\
\hline Heart failure & $0.53(0.38,0.72)$ & $<0.001$ & $0.66(0.47,0.91)$ & 0.01 \\
\hline Hypertension & $0.96(0.76,1.22)$ & NS & - & - \\
\hline Diabetes & $0.86(0.64,1.17)$ & NS & - & - \\
\hline Ischemic stroke & $1.00(0.70,1.44)$ & NS & - & - \\
\hline AF as primary diagnosis & $3.24(2.52,4.17)$ & $<0.001$ & $3.0(2.3,3.9)$ & $<0.001$ \\
\hline Hemorrhagic stroke & $0.34(0.12,1.02)$ & 0.06 & $0.44(0.14,1.34)$ & NS \\
\hline Reminder intervention & $1.5(1.1,2.1)$ & 0.004 & $1.54(1.13,2.12)$ & 0.007 \\
\hline
\end{tabular}

* Multivariable model includes age (per 10 years), female gender, heart failure, AF as primary diagnosis, hemorrhage stroke, and reminder intervention. $\mathrm{AF}=$ atrial fibrillation; $\mathrm{AFL}=$ atrial flutter; $\mathrm{ED}=$ emergency department; $\mathrm{NS}=$ not significant; $\mathrm{OAC}=$ oral anticoagulation.

when adjusted for age, history of heart failure, prior hemorrhagic stroke, and AF as the primary ED discharge diagnosis. A history of heart failure was associated with lower rates of OAC initiation.

To assess the impact of the ED facility on OAC initiation, we performed a separate analysis limited to the pre-intervention, observational phase $(\mathrm{N}=713)$. The ED facility was not predictive of OAC initiation among OACnaïve $\mathrm{AF} / \mathrm{AFL}$ patients following an $\mathrm{ED}$ discharge.

\section{DISCUSSION}

Among patients with AF/AFL discharged directly from the $\mathrm{ED}$, the initiation of guideline-recommended OAC therapy remains low. In this study, a simple intervention, consisting of a reminder statement and decisionsupport package resulted in a significant increase in the rate of appropriate OAC therapy.

\section{Barriers to OAC therapy initiation in the ED}

As a frequent point of contact for many AF/AFL patients, ED physicians are in a unique position to facilitate appropriate guideline-directed OAC therapy for AF/AFL patients. Further highlighting the importance of the ED physician is the finding that an initiation of OAC therapy prior to discharge from the ED can lead to a greater longterm adherence. ${ }^{11}$ It remains unclear why the rates of initiation of OAC therapy in patients with AF/AFL discharged from EDs remain consistently low. In a survey of emergency physicians in Spain who explored reasons for not prescribing $\mathrm{OAC}$, almost $50 \%$ of ED physicians cited the "lack of indications" (due to the perception of a low risk of stroke), despite patients meeting criteria for anticoagulation as per guideline recommendations. ${ }^{12}$ Thirty-three percent of ED physicians deemed antiplatelet monotherapy an adequate stroke prophylaxis, and only $5.6 \%$ of physicians referred to other care providers to assess the need for OAC.

Several potential barriers to OAC initiation in the ED have been raised, such as inadequate time to discuss the risks and benefits of anticoagulation, inability to ensure adequate follow-up, or pedagogical differences in ED physicians' practice of stroke prevention. ${ }^{18,19}$ Furthermore, reluctance to prescribe OAC may stem from the practice behaviours when warfarin was the sole oral anticoagulant option. Given the complexity of initiating warfarin and ensuring ongoing monitoring, OAC initiation in the ED can be challenging and unpalatable, especially considering regional variability in the accessibility of multidisciplinary supports (e.g., anticoagulation clinic and $\mathrm{AF}$ clinic). ${ }^{20}$ Additionally, addressing an issue of long-term risk may become a secondary consideration when there are other acutely ill patients to manage.

Nevertheless, if not directly initiating anticoagulation, ED physicians still have a pivotal role in facilitating outpatient referrals to optimize management of patients with AF/AFL. In our study, we assessed OAC initiation within 90 days of an index visit, which would capture OAC initiation directly within the ED or facilitated via a consultant referral (i.e., assessment and management of stroke prevention in AF/AFL delegated to a family physician, internist, or cardiologist). 
Interestingly, despite the availability of consultant services, only $38.8 \%$ of OAC-naïve patients with $\mathrm{AF} / \mathrm{AFL}$ were started on appropriate OAC therapy within 90 days of an ED discharge. This rate is similar to previous studies that had examined the rate initiation of OAC in the ED prior to discharge. ${ }^{12-14}$ Therefore, there still remains a significant care gap and potential lost opportunity in the management of AF/AFL with regards to stroke prevention.

Few studies have directly assessed the impact of interventions on OAC prescription within the ED setting. Skolarus et al. found that there was no difference in rates of warfarin use after implementing their intervention of mailing letters to patients and their family physicians following an ED evaluation. ${ }^{21}$ The negative results are not unexpected; prior meta-analyses demonstrate that printed educational letters have limited efficacy. ${ }^{22}$ Coll-Vinent et al. showed a significant increase in the rate of warfarin prescriptions by ED physicians following an implementation of an AFtreatment protocol consisting of a pocket brochure and physician education sessions. ${ }^{23}$ However, due to the nature of the study design, including lack of an adequate control, there are limitations in the generalizability of the study.

In our study, the implementation of a simple quality improvement strategy resulted in a significant improvement in appropriate OAC therapy in patients directly discharged from EDs. Our findings align with previous evidence demonstrating improved patient care through the implementation of standardized order sets or checklists. ${ }^{24,25}$ The impact of our intervention, which included a paper-based reminder, was larger compared with previous attempts using automated electronic reminders in a family practice setting, ${ }^{26}$ or an inpatient setting. ${ }^{27}$ Therefore, the implementation of decision-making algorithms either as a stand-alone paper-based system or integration into computerbased order sets can lead to improved care of patients with $\mathrm{AF} / \mathrm{AFL}$ in EDs.

\section{Risk-treatment paradox}

In our cohort, patients with an older age and patients with a history of heart failure were less likely to be initiated on OAC following their discharge from the EDs. Reasons for underutilization of OAC in this population are unclear. One possibility is that these patients were frailer and had additional comorbidities that would preclude OAC initiation. It is important to note that therapy should be tailored to each individual patient by assessing the risk of stroke and balancing that to the risk of major bleeding. ${ }^{2}$ The use of administrative databases in our study is unlikely to capture the nuances of physician decision-making, which may account for the underutilization of OAC prescription in the heart failure population with AF/AFL.

Another explanation may reflect the discord between the bleeding risk estimated using validated risk scores and physician-assigned risk. In our study, the increased OAC initiation rates resulting from the intervention were limited to patients with lower CHADS65 scores (i.e., scores of 1 to 2) compared with higher CHADS65 scores (i.e., CHADS65 of > 2). Although our study was not powered to differentiate OAC initiation rates stratified by the CHADS65 score, the results of this exploratory analysis are consistent with the so-called "risk-treatment paradox." ${ }^{28}$ Unfortunately, our current stratification tools of stroke risk and complications from anticoagulation are imprecise, and clinical judgement may result in an overestimation of risk compared with benefit; that is, physicians may underutilize appropriate anticoagulation in patients with the highest stroke risk due to an exaggerated perception of fall or bleed risk. ${ }^{29}$ More precise risk stratification tools could help address this issue and improve rates of anticoagulation in populations that would derive the greatest benefit.

\section{Limitations}

Our study has several important limitations. This study was observational and therefore inherently susceptible to confounding factors. Furthermore, due to the non-randomized nature of the study, there may be prognostic differences between the intervention and control groups. During the intervention phase of the study, we relied on a preliminary interpretation of rhythm based on an automated ECG machine algorithm. A review of these ECGs by a cardiac electrophysiologist revealed that the machine algorithm correctly identifies AF/AFL more than $99 \%$ of the time. Our intervention also stated that the diagnosis of AF/AFL should be confirmed by a physician. We identified patients with AF/AFL by relying solely on ECG documentation of such rhythm while they were in the ED and did not identify patients without an ECG performed or those with paroxysmal AF/AFL who were in sinus rhythm while in the ED. Our intervention was labour intensive 
because it required the manual addition of a reminder sticker to ECGs at the time that they were obtained as well as attachment of the decision-making algorithm, potentially limiting the generalizability to other EDs with more limited resources. However, most modern ECG machines could be programmed to automatically include the reminder statement used in this study. It is possible that the temporal increase in OAC prescriptions in the ED-intervention groups was due to factors in addition to than the reminder intervention, which we were not able to control for, given the study design. However, the similar baseline (pre-intervention) rates of anticoagulation between ED-intervention and EDcontrol groups would argue against any substantive differences. Lastly, we relied on an external database to identify OAC prescriptions within 90 days. This database captures prescriptions that are dispensed only, so it may underestimate the total number of OAC prescriptions written by ED physicians and does not account for patient adherence. We did not explore the patient factors that may lead patients to fill or not fill an OAC prescription, nor did we examine patient adherence beyond 90 days.

\section{CONCLUSION}

In our study, implementation of a quality improvement intervention, consisting of a simple reminder and a decision-support tool, significantly increased the appropriate initiation of $\mathrm{OAC}$ within 90 days in highrisk AF/AFL patients discharged from the ED. Additional study is warranted to explore the potential barriers to $\mathrm{OAC}$ initiation in the ED.

Acknowledgements: We would like to thank all of the cardiology technologists in the Calgary Health Region for their participation in this project. We also thank Mingkai Peng for assistance with the statistical analysis. Drs. Chew and Rezazadeh are members of the Cardiac Arrhythmia Network of Canada (CANet) HQP Association for Trainees (CHAT), and Dr. Quinn is a CANet Network Investigator.

Financial support: This study was supported by the Canadian Cardiovascular Society Bayer Resident Award.

Competing interests: None declared.

\section{SUPPLEMENTARY MATERIALS}

To view supplementary material for this article, please visit https://doi.org/10.1017/cem.2018.415

\section{REFERENCES}

1. Wolf PA, Abbott RD, Kannel WB. Atrial fibrillation as an independent risk factor for stroke: the Framingham study. Stroke 1991;22(8):983-8.

2. Macle L, Cairns J, Leblanc K, et al. 2016. focused update of the Canadian Cardiovascular Society guidelines for the management of atrial fibrillation. Can 7 Cardiol 2016;32 (10):1170-85.

3. Miller PS, Andersson FL, Kalra L. Are cost benefits of anticoagulation for stroke prevention in atrial fibrillation underestimated? Stroke 2005;36(2):360-6.

4. Giugliano RP, Ruff CT, Braunwald E, et al. Edoxaban versus warfarin in patients with atrial fibrillation. $N$ Engl 7 Med 2013;369(22):2093-104.

5. Patel MR, Mahaffey KW, Garg J, et al. Rivaroxaban versus warfarin in nonvalvular atrial fibrillation. $N$ Engl $7 \mathrm{Med}$ 2011;365(10):883-91.

6. Connolly SJ, Ezekowitz MD, Yusuf S, et al. Dabigatran versus warfarin in patients with atrial fibrillation. $N$ Engl 7 Med 2009;361(12):1139-51.

7. Granger CB, Alexander JH, McMurray JJ, et al. Apixaban versus warfarin in patients with atrial fibrillation. $N$ Engl 7 Med 2011;365(11):981-2.

8. Atzema CL, Austin PC, Miller E, et al. A population-based description of atrial fibrillation in the emergency department, 2002 to 2010. Ann Emerg Med 2013;62(6):570-577e7.

9. Sandhu RK, Bakal JA, Ezekowitz JA, McAlister FA. The epidemiology of atrial fibrillation in adults depends on locale of diagnosis. Am Heart 7 2011;161(5):986-992e1.

10. Miyasaka Y, Barnes ME, Gersh BJ, et al. Secular trends in incidence of atrial fibrillation in Olmsted County, Minnesota, 1980 to 2000, and implications on the projections for future prevalence. Circulation 2006;114(2):119-25.

11. Atzema CL, Austin PC, Chong AS, et al. The long-term use of warfarin among atrial fibrillation patients discharged from an emergency department with a warfarin prescription. Ann Emerg Med 2015;66(4):347-354e2.

12. Coll-Vinent B, Martin A, Malagon F, et al. Stroke prophylaxis in atrial fibrillation: searching for management improvement opportunities in the emergency department: the HERMES-AF study. Ann Emerg Med 2015;65(1):1-12.

13. Scheuermeyer FX, Innes G, Pourvali R, et al. Missed opportunities for appropriate anticoagulation among emergency department patients with uncomplicated atrial fibrillation or flutter. Ann Emerg Med 2013;62(6): $557-565 \mathrm{e} 2$.

14. Scott-Herridge JA, Seifer CM, Steigerwald R, et al. A multihospital analysis of predictors of oral anticoagulation prescriptions for patients with actionable atrial fibrillation who attend the emergency department. Acute Card Care 2017;3:1-8.

15. Southern DA, Norris CM, Quan H, et al. An administrative data merging solution for dealing with missing data in a clinical registry: adaptation from ICD-9 to ICD-10. $B M C$ Med Res Methodol 2008;8:1.

16. Di Biase L. Use of direct oral anticoagulants in patients with atrial fibrillation and valvular heart lesions. 7 Am Heart Assoc 2016;5(2). 
17. Verma A, Cairns JA, Mitchell LB, et al. 2014. focused update of the Canadian Cardiovascular Society guidelines for the management of atrial fibrillation. Can 7 Cardiol 2014;30(10):1114-30.

18. Atzema CL. Stroke prevention for high-risk atrial fibrillation in the emergency setting: the emergency physician perspective. Can $\mathcal{7}$ Cardiol 2018;34(2):125-31.

19. Barrett TW, Vermeulen MJ, Self WH, et al. Emergency department management of atrial fibrillation in the United States versus Ontario, Canada. 7 Am Coll Cardiol 2015; 65(20):2258-60.

20. Barrett TW, Marill KA. Anticoagulation for emergency department patients with atrial fibrillation: is our duty to inform or prescribe? Ann Emerg Med 2013;62(6):566-8.

21. Skolarus LE, Morgenstern LB, Scott PA, et al. An emergency department intervention to increase warfarin use for atrial fibrillation. 7 Stroke Cerebrovasc Dis 2014;23(2): 199-203.

22. Grudniewicz A, Kealy R, Rodseth RN, et al. What is the effectiveness of printed educational materials on primary care physician knowledge, behaviour, and patient outcomes: a systematic review and meta-analyses. Implement Sci 2015; 10:164.

23. Coll-Vinent B, Pacheco G, Junyent $M$, et al. Impact of implementing common guidelines at different care levels in a healthcare area on the improvement of atrial fibrillation treatment. Rev Esp Cardiol 2007;60(4):392-403.

24. Chin HL, Wallace P. Embedding guidelines into direct physician order entry: simple methods, powerful results. Proc AMIA Symp 1999;1: 221-5.

25. Milani RV, Lavie CJ, Dornelles AC. The impact of achieving perfect care in acute coronary syndrome: the role of computer assisted decision support. Am Heart 7 2012; 164(1):29-34.

26. Robson J, Dostal I, Mathur R, et al. Improving anticoagulation in atrial fibrillation: observational study in three primary care trusts. Br 7 Gen Pract 2014;64(622): e275-81.

27. Silbernagel G, Spirk D, Hager A, et al. Electronic alert system for improving stroke prevention among hospitalized oral-anticoagulation-naive patients with atrial fibrillation: a randomized trial. 7 Am Heart Assoc 2016;5:e003776.

28. Sandhu RK, Bakal JA, Ezekowitz JA, McAlister FA. Risk stratification schemes, anticoagulation use and outcomes: the risk-treatment paradox in patients with newly diagnosed non-valvular atrial fibrillation. Heart 2011;97(24):2046-50.

29. Tan AY, Ellenbogen KA. Comparing the imperfect with the imperfect: the imprecise science of assessing the risk and benefits of anticoagulation in atrial fibrillation. Circulation 2014;129(20):1997-9. 